\title{
The Complexities of Individual Financial Conflicts of Interest
}

\author{
Eugene H Rubin*, I \\ 'Department of Psychiatry, Washington University School of Medicine, St Louis, MO, USA
}

\begin{abstract}
Academic health centers (AHCs) are unique resources that are critical for the advancement of science and the training of health care providers, scientists, and educators. AHCs depend on public trust. Certain financial relationships between medical school faculty and industry create situations that have the potential to be deleterious to AHCs. Yet, the translation of clinically relevant, scientific advances to products that directly impact patients' lives benefits from entrepreneurial activities, and such activities necessitate interactions between academia and industry. Society has a vested interest in protecting human research participants, maintaining objectivity in scientific research, and encouraging creative research with clinical applications. Conflicts of interest (COI) committees have been created by AHCs to evaluate faculty financial $\mathrm{COI}$ and to develop strategies to eliminate, reduce, or manage such conflicts. Issues involving financial $\mathrm{COI}$ are relevant to psychiatry. These issues are reviewed from the perspective of regulatory oversight provided by a medical school's COI committee.

Neuropsychopharmacology (2005) 30, I -6, advance online publication, 6 October 2004; doi: 1 0. 1 038/sj.npp. 1300576
\end{abstract}

Keywords: academic medical centers; biomedical research; conflict of interest; entrepreneurship; ethics; faculty medical

\section{INTRODUCTION}

Over the last several years, issues regarding 'conflicts of interest (COI)' have received considerable attention. Many reports have appeared in the press describing inappropriate and unprofessional behaviors attributed to financial COI. Serious consequences can result when investigators involved in research engage in these behaviors, including the erosion of the public's trust in academic health centers (AHCs). Psychiatric investigators are not immune to matters related to financial COI. Many AHCs utilize COI committees to examine issues involving academicians and financial COI. The purpose of this article is to review issues pertaining to financial COI and to sensitize readers to the significance of this topic. The author is a psychiatrist who is the chair of a medical school's COI committee. This article is written from the perspective of the regulatory and oversight roles COI committees serve in helping to provide solutions to this increasingly complex area.

\section{BACKGROUND}

Issues involving financial COI are better understood in the context of a brief historical perspective. As stated in the

\footnotetext{
* Correspondence: Dr EH Rubin, School of Medicine, Department of Psychiatry, Washington University, Campus Box 8134, 660 South Euclid, St Louis, MO 63II0-I093, USA, Tel: + 314362 2462, Fax: + 314362 0193, E-mail: rubing@wustl.edu

Received 20 April 2004; revised 7 July 2004; accepted 19 August 2004 Online publication: 24 August 2004 at http://www.acnp.org/citations/ NPP08230404 |80/default.pdf
}

1915 Declaration of Principles of the American Association of University Professors: 'All true universities, whether public or private, are public trusts designed to advance knowledge by safeguarding the free inquiry of impartial teachers and scholars. Their independence is essential because the university provides knowledge not only to its students, but also to the public agency in need of expert guidance and the general society in need of greater knowledge; and ... these latter clients have a stake in disinterested professional opinion, stated without fear or favor, which the institution is morally required to respect' (American Association of University Professors, 1954; AAMC Task Force on Financial Conflicts of Interest in Clinical Research, 2003; Korn, 2002).

The public expects faculty of AHCs to be acting in society's best interest and not to be making decisions based on their own financial interest. As described by Ludmerer in his seminal book Time to Heal, there has been a 'decline of academic health centers as public trusts,' which began in the 1970s (Ludmerer, 1999, p 337). AHCs have become more business-oriented over the last several decades, and faculty have experienced increased pressure to generate income. 'As market forces became stronger and more hostile, it was understandable that academic health centers became more businesslike and adopted corporate strategies. Yet as they did, an extraordinary inversion occurred: they began to lose sight of their mission and raison d'être' (Ludmerer, 1999, p 365). The academic mission of doing good through scholarly activities, including teaching and research, became strongly influenced by financial considerations. This increased emphasis on income generation has come at a time when many physicians are coping with substantial personal educational debt. 
The implementation in 1981 of the Bayh-Dole Act, which encourages the commercialization of discoveries resulting from federally funded research, contributed to academia's interest in increasing relationships with industry (BayhDole Act, 1980). One goal of this legislation is to encourage the translation of scientific results generated in academic centers into products that directly benefit society by allowing universities and investigators to patent discoveries and then to license those patents. In effect, it encourages faculty and universities to be entrepreneurial. Since its passage, there has been dramatic growth of invention disclosures, patent applications, patents issued, new companies formed, revenue generated, and new products developed (Association of University Technology Managers, 2003; Gelijns and Their, 2002; Mowery et al, 2001; Rai and Eisenberg, 2003). These three factors - increased attention of AHCs to fiscal issues, substantial physician debt, and the encouragement of entrepreneurialism by the Bayh-Dole Act - have contributed to many academic investigators becoming more attuned to financial issues.

\section{FINANCIAL COI, GUIDELINES, AND MANDATES}

Most mandates or policies utilize the term 'financial COI' when there is concern that personal financial relationships between investigators and business could reasonably be expected to have the potential to influence the decisionmaking of the investigators. Since no one, especially the individual with the financial COI, can determine the effect of a particular financial interest on an individual's thinking or behavior (Choudhry et al, 2002; Warner and Gluck, 2003), guidelines and mandates define thresholds above which there is considerable concern that financial COI exist and, therefore, that the specific circumstances should be carefully examined.

The published guidelines and mandates address different, but related, issues. For nonfederal research, including research involving human participants, there is a large range in what is considered financially significant (Cho et al, 2000; Warner and Gluck, 2003; Boyd et al, 2004). For example, some consider any financial relationship as being significant while other institutions have established financial thresholds in the range of $\$ 10000-\$ 20000$ of additional annual income. Policies pertaining to financial COI involving federally funded research are federally mandated. Rule 42CFR part 50 covers Public Health Service funded research and addresses the protection of research integrity. Its purpose is to help maintain an investigator's objectivity regarding the design, conduct, and reporting of the research (Public Health Service, 1995). Published in 1995, this policy requires creation of strategies to manage significant financial COI. The financial value of 'significant' is $\$ 10000$ per year in personal income resulting from royalties, honoraria, consultation fees, equity holdings, etc, as well as ownership interest of more than $5 \%$.

In 2001, the American Association of Medical Colleges (AAMC) published guidelines designed to protect human research participants from possible negative consequences resulting from financial COI (AAMC Task Force on Financial Conflicts of Interest in Clinical Research, 2003). These guidelines propose that investigators should not participate in a clinical research project when they have more than $\$ 10000$ per year of personal income from companies with financial interest in the outcome of the research (The policy at Washington University follows the AAMC's recommendations (http://medcoi.wustl.edu)). In mid-2004, the Department of Health and Human Services published guidelines in the Federal Registry dealing with similar issues in a report entitled 'Financial Relationships and Interests in Research Involving Human Subjects: Guideline for Human Subject Protection' (Department of Health and Human Services, 2004).

In 2001, a set of guidelines was developed by a group of medical journals to insure that authors have appropriate access to the data and fully disclose any financial relationships relevant to the reported research (Davidoff et al, 2001). Such disclosures provide transparency to the reader concerning financial relationships that conceivably could influence the author's perspective concerning the material being presented.

Two additional sets of guidelines related to the general area of COI involve the pharmaceutical industry specifically. One addresses the conduct of clinical trials and communication of the results of these trials (Pharmaceutical Research and Manufacturers of America, 2002); the other addresses interactions between industry and physicians (Pharmaceutical Research and Manufacturers of America, 2004).

As previously noted, the government has specific rules regarding individual financial COI and federally funded research (Public Health Service, 1995; Cho et al, 2000; Henderson and Smith, 2002; Korn, 2002; Lo et al, 2000). When these policies are not followed, there can be significant consequences for the academic institution involved. The nonfederal guidelines listed above are not mandates but, rather, recommendations by leading organizations. The hope is that these guidelines will be voluntarily implemented. If AHCs can self-regulate by following these guidelines, it may alleviate some of the concerns of federal agencies and perhaps prevent additional federal regulations. COI committees serve as part of the internal oversight process.

\section{COI AND AHCs}

COI issues, coupled with an ever increasing number of examples where financial COI have been linked (justifiably or unjustifiably) to inappropriate behaviors on the part of academicians and to bad outcomes, are problematic for AHCs. AHCs are critically dependent on the public trust in order to attract public support and financial support, including research funding. In order to maintain the public trust, many AHCs have created or enhanced COI committees to review issues involving faculty financial COI and are developing rigorous strategies to address these issues. These strategies are just one piece of a larger picture of regulations designed to maximize safety of humans participating in research and insure research integrity; however, it is a very visible piece and, therefore, has high value to AHCs.

The author's basic assumption is that the overwhelming majority of people involved in academia (faculty and administration), industry, and policymaking are well 
intentioned, bright people interested in doing a good job and doing the right thing. Key responsibilities of these various groups (AHCs, industry, and regulatory agencies) overlap in certain ways but are quite different in other ways. These differences can lead to competing interests. AHCs advance knowledge through research, administer state-of-the-art clinical care, and provide teaching for the next generation of health care providers. Health-related industries produce products that help society. For-profit industry's portfolios of products must be financially viable as well as support fiscal responsibilities to shareholders. Marketing is an important part of business for industry. Some of the responsibilities of regulatory agencies include protecting society and responding to public concerns.

Academic faculty members possess intellectual and creative skills and knowledge that can be useful to academia, industry, and the government. A strong argument can be made that there are benefits to society when leaders of academia interact with leaders of industry. The research techniques and approaches used in industry and academia are often complementary. AHCs are incubators for creative ideas. Most medical centers have neither the resources nor the business expertise to take ideas from the benchside and make them applicable to the bedside. Industries, such as those involving pharmaceuticals or medical devices, have the technology, scientific expertise, business sophistication, and entrepreneurial spirit to make an idea into a reality. Partnerships between academia and industry are important if society is to achieve the maximum benefit from the financial support of AHCs.

When a faculty member consults with industry, financial relationships are usually established between the faculty member and the company. By the nature of the complex and sometimes competing goals of industry and academia, faculty can be caught in the middle of opposing interests. A key purpose of COI committees is to try to understand the nature of the competing interests and develop strategies that help protect research participants, research integrity, society, AHCs, as well as the academicians, themselves. The committee benefits when there is significant faculty representation on the committee with expertise about the various issues.

The cause for concern about the influence of COI is legitimate (Bodenheimer, 2000; DeAngelis et al, 2001; Moses and Martin, 2001; Choudhry et al, 2002; Morin et al, 2002; Moses et al, 2002; Steinbrook, 2002a, b, 2004; Yarborough and Sharp, 2002; Bekelman et al, 2003; Johns et al, 2003; Warner and Gluck, 2003; Blumenthal, 2003). Unfortunately, situations have occurred involving breaches of research integrity and concerns about integrity of publications. Examples that have received media attention include the suspension of federally supported research at several major medical schools because of concerns regarding protection of research participants. These have included investigations involving deaths of research participants. Recently, concerns about COI involving investigators at the NIH have surfaced that are leading to major revisions of financial COI policies at this agency. Concerns have also been expressed about the influence of financial COI on medical education (Relman, 2001, 2003). Public trust is threatened by repeated examples of problems that appear to the public to be related to financial considerations by faculty members. The government is sensitive to public opinion. Dramatic examples of perceived, problematic behavior of academicians associated with disastrous outcomes could lead to political and regulatory intervention.

Data generated from research of financial COI are limited. A recent review of the existing data provides some guidance (Warner and Gluck, 2003). Financial COI are not rare. It is known that it is difficult for individuals to be objective about their own COI, and it is common for people to feel that they are less vulnerable to COI than their peers. Behavior can be changed by financial COI. It is difficult, if not impossible, for anyone to determine how financial COI may influence an individual, including the person himself (Warner and Gluck, 2003; Choudhry et al, 2002). Recent work has demonstrated that the majority of research participants want to know about the financial COI of the investigators involved with the study. Certain types of financial COI would cause a significant minority of potential research participants to consider not participating in the research (Kim et al, 2004). Therefore, it is important for an impartial committee to help an AHC, academicians, and research participants better understand potential COI and recommend strategies for managing these conflicts.

\section{THE ROLE OF COI COMMITTEES}

The presence of COI does not necessarily mean that the conflict is causing inappropriate behavior. Indeed, it is often impossible to know the influence of financial COI on any individual (Choudhry et al, 2002; Warner and Gluck, 2003). Therefore, AHCs are becoming increasingly cautious and requiring careful examination of individual situations whenever specific financial limits are exceeded.

A financial COI pertaining to research indicates that financial incentives exist that outside observers could reasonably believe might create bias in the way an investigator designs, conducts, analyzes, or reports a research project. If clinical research is involved, a financial COI has the potential to cause the investigator to consider financial issues in a manner that is not in the best interest of research participants. The purpose of a faculty-based, COI committee is to evaluate the specific issues involved and recommend a management strategy that considers the protection of research participants, scientific issues, societal issues, and financial issues in the context of the mandates and guidelines already reviewed. The Committee attempts to protect research participants, the AHC, and the academician, while, simultaneously, avoiding the harm to society that would occur by the prevention of advances in research. A management strategy helps protect academicians because, should an inadvertent bad outcome occur, the AHC can demonstrate to the public and investigating agency that reasonable management strategies were in place, and that financial COI, if present, were not likely related to the bad outcome. A management strategy helps protect an AHC in terms of demonstrating to the public that the AHC is serious about maintaining public trust. 


\section{TWO CASE STUDIES}

The following examples illustrate hypothetical cases involving a psychiatry faculty member and a COI committee.

\section{Case 1: Device Royalties and COI}

Case summary. A psychiatrist developed an idea for a new device for the treatment of severe depression. The psychiatrist and his university patented the device. A company licensed the patent and has developed the device to the point that it is ready for human testing. If the device were commercially successful, the psychiatrist would receive payments that were related to the number of units sold. The psychiatrist requests to be involved in testing the device in human subjects. Furthermore, the psychiatrist wishes to be involved in the interpretation of the results and the writing of related papers.

Nature of the conflict. The psychiatrist has a financial interest in the success of the device. Early clinical studies often examine the safety of the procedure and develop preliminary data regarding efficacy. The financial COI might influence the psychiatrist's judgment regarding the design of the study, the recruitment of research participants, or the appropriate use of the device. Furthermore, the financial COI could influence objectivity in interpreting the study results.

Management strategy. A COI committee would likely want to know whether the testing of the device required the unique expertise of the inventor/psychiatrist. If the actual testing did not require the expertise of the psychiatrist, the testing of the device should be independent of the inventor. The analysis of data and interpretation of the data should also be independent of the inventor. Full disclosure of the financial COI would be appropriate on publications and talks. If the inventor's expertise were necessary for the safe use of the device, then a management strategy would likely require substantial oversight by co-investigators who were without financial COI. If the initial testing demonstrated promising results and larger, multisite, controlled studies were to be done, then investigators without significant financial COI should be involved in the design, conduct, and analysis of such studies. Since the inventor has such a large financial interest in the outcome, it is best that there be distance between the inventor and the larger, efficacy studies. Requiring full disclosure and full transparency in terms of the inventor's participation in publications or presentations would likely be part of a management strategy.

Discussion. The guiding principle in this case is that it is most prudent to separate the testing of a device from an investigator who has a substantial financial interest in the outcome, unless a convincing argument can be made that the unique expertise of that individual is necessary for the safety of the research participants or for the adequate testing of the device. If that were the case, then oversight of the involvement would be necessary. Full disclosure would be required in all relevant communications. This strategy minimizes the potential that financial COI influence the clinical testing while allowing the testing of the device to proceed and the investigator to financially benefit should the device be successful.

\section{Case 2: Consulting and/or Speaking Fees and Clinical Studies}

Case summary. A psychiatrist receives $\$ 30000$ annually for consulting with a large pharmaceutical company. In addition, the psychiatrist receives another $\$ 30000$ annually from the same company for giving non-CME talks. The psychiatrist is interested in participating as a key investigator for a drug trial sponsored by this company.

Nature of the conflict. The psychiatrist has considerable financial relationships with this company. Furthermore, the company could adjust this financial relationship by varying the number of speaking opportunities or by changing the financial remuneration per talk or per consultation visit. The degree to which financial relationships might influence an investigator's judgment regarding the recruitment of patients, evaluation and interpretation of side effects, as well as the interpretation, analysis, and reporting of data, cannot be determined. The level of the investigator's role in the design of the study and the interpretation and presentation of the results is important information for the COI committee to address when reviewing the investigator's COI.

Management strategy. If it were evident that the investigator could have significant influence on human safety or data interpretation or presentation, the Committee would likely request that the investigator choose between actively participating in the study or maintaining his previous financial relationships with that company, ie eliminate the COI. This strategy depends upon the assumption that the study could continue without the investigator's participation, and that, therefore, overall progress would not be impeded. Two circumstances under which the Committee might consider exceptions to this strategy include: (1) the investigator has critical expertise necessary for completion of the study or (2) the study is a multisite, double-blind, placebo-controlled trial and the investigator is not involved in the recruitment of participants, interpretation of sideeffects, interpretation of the data or presentation of results. In these cases, the Committee would determine an alternate management strategy. The role of the investigator in publishing or presenting the results of the study would be examined and, at a minimum, full disclosure of the financial relationship would be required.

Discussion. The core issue involved in this example is that no one can determine the influence of a large amount of money on an investigator's judgment involving a drug study. The more involved an investigator is in the recruitment, evaluation, interpretation, and communication of results, the more serious the concerns about influence. Furthermore, there are difficult issues involved with reconciling the importance of faculty being 'impartial teachers and scholars' who demonstrate 'disinterested professional opinion' (American Association of University 
Professors, 1954) and the payment of substantial sums of money for services that could be viewed as assistance in pharmaceutical marketing.

\section{FUTURE DIRECTION}

Issues related to financial COI involve a lot more than just money. They are part of a bigger picture involving protection of research participants and research integrity. Since AHCs realize that their future success is closely related to maintaining and enhancing public trust, such centers will increasingly be requiring that academicians be above reproach.

The topic of financial COI would benefit from more knowledge gained through research. Warner and Gluck (2003) outline some of the key research questions pertaining to financial COI. Learning more about the true effectiveness, benefits, and risks of management strategies will allow a more data driven approach. Gathering information about the prevalence and nature of financial relationships will help in understanding the magnitude of the issue. Enhanced insight into true public opinion will aid in better defining the issues. Answers to such research questions will allow a better understanding about the prevalence of COI, the influence of COI, and the effectiveness of management of COI. More data will allow a clearer understanding of future directions. Academicians can help by supporting such research endeavors.

Faculty can also help by enhancing their own education on these and related topics and teaching others about financial COI (Warner and Gluck, 2003). It would be beneficial if faculty would encourage educational curricula at universities and national organizations. It will be increasingly critical to let the public know that we are regulating ourselves and are willing to be fully transparent regarding financial COI. Without self-regulation, it is highly likely that there will be significant federal mandates. Such mandates may not allow for peer review or other mechanisms that provide reasonable balance among complex competing interests.

\section{CONCLUSION}

Successful academicians are often viewed as 'thought leaders' and as such have strong influence on future researchers, clinicians, educators, and clinicians. Such faculty have tremendous responsibility to remain 'impartial.' AHCs have increasing need to maintain or restore public trust. Academicians can receive substantial compensation for consulting with industry by providing unique and important services, and such compensation can lead to financial COI. Therefore, a necessary tension is generated when trying to balance the competing goals of minimizing individual financial COI and facilitating the translation of scientific discoveries to products that benefit society. A dynamic equilibrium occurs from the iterative process of university COI committees developing individual management strategies based on current policies, guidelines, and specific circumstances. The goal of this dynamic equilibrium is to maximize the safety of research participants, protect the integrity of research, and, at the same time, minimize the disruption to the entrepreneurial process of scientific advancement. These issues are likely to have increased impact on academic investigators as the relationship between academia and industry continues to evolve.

\section{ACKNOWLEDGEMENTS}

Dr Rubin has no financial conflicts of interest that have the potential to bias this work.

\section{REFERENCES}

AAMC Task Force on Financial Conflicts of Interest in Clinical Research (2003). Protecting subjects, preserving trust, promoting progress I: policy and guidelines for the oversight of individual financial interests in human subjects research. Acad Med 78: 225-236.

American Association of University Professors (1954). Declaration of principles (1915). Bull Am Assoc University Professors 40: No. 1.

Association of University Technology Managers, Inc. (2003). AUTM licensing survey: FY 2002 survey summary. Available at: http://www.autm.net/index_ie.html Accessed April 16, 2004.

Bayh-Dole Act (1980). Pub L No. 96-517, 35USC.

Bekelman JE, Li Y, Gross CP (2003). Scope and impact of financial conflicts of interest in biomedical research: a systematic review. JAMA 289: 454-465.

Blumenthal D (2003). Academic-industrial relationships in the life sciences. $N$ Engl J Med 349: 2452-2459.

Bodenheimer $\mathrm{T}$ (2000). Uneasy alliance: clinical investigators and the pharmaceutical industry. $N$ Engl J Med 342: 1539-1544.

Boyd EA, Lipton S, Bero LA (2004). Implementation of financial disclosure policies to manage conflicts of interest. Health Aff 23: 206-214.

Cho MK, Shohara R, Schissel A, Rennie D (2000). Policies on faculty conflicts of interest at US universities. JAMA 284: 2203-2208.

Choudhry NK, Stelfox HT, Detsky AS (2002). Relationships between authors of clinical practice guidelines and the pharmaceutical industry. JAMA 287: 612-617.

Davidoff F, DeAngelis CD, Drazen JM, Hoey J, Hojgaard L, Horton $\mathrm{R}$ et al (2001). Sponsorship, authorship, and accountability. JAMA 286: 1232-1234.

DeAngelis CD, Fontanarosa PB, Flanagin A (2001). Reporting financial conflicts of interest and relationships between investigators and research sponsors. JAMA 286: 89-91.

Department of Health and Human Services (2004). Financial relationships and interests in research involving human subjects: guidance for human subject protection. Fed Regist 69: 26393-26397.

Gelijns AC, Thier SO (2002). Medical innovation and institutional interdependence: rethinking university-industry connections. JAMA 287: 72-77.

Henderson JA, Smith JJ (2002). Financial conflict of interest in medical research: overview and analysis of federal and state controls. Food Drug Law J 57: 445-456.

Johns MME, Barnes M, Florencio PS (2003). Restoring balance to industry-academia relationships in an era of institutional financial conflicts of interest: promoting research while maintaining trust. JAMA 289: 741-746.

Kim SYH, Millard RW, Nisbet P, Cox C, Caine ED (2004). Potential research participants' views regarding researcher and institutional financial conflicts of interest. J Med Ethics 30: 73-79.

Korn D (2002). Industry, academia, investigator: managing the relationships. Acad Med 77: 1089-1095. 
Lo B, Wolf LE, Berkeley A (2000). Conflict-of-interest policies for investigators in clinical trials. $N$ Engl J Med 343: 1616-1620.

Ludmerer KM (1999). Time to Heal: American Medical Education from the Turn of the Century to the Era of Managed Care. Oxford University Press: Oxford. 514pp.

Morin K, Rakatansky H, Riddick FA, Morse LJ, O'Bannon JM, Goldrich MS et al (2002). Managing conflicts of interest in the conduct of clinical trials. JAMA 287: 78-84.

Moses H, Braunwald E, Martin JB, Thier SO (2002). Collaborating with industry - choices for the academic medical center. $N$ Engl J Med 347: 1371-1375.

Moses H, Martin JB (2001). Academic relationships with industry: a new model for biomedical research. JAMA 285: 933-935.

Mowery DC, Nelson RR, Sampat BN, Ziedonis AA (2001). The growth of patenting and licensing by US universities: an assessment of the effects of the Bayh-Dole act of 1980. Res Policy 30: 99-119.

Pharmaceutical Research and Manufacturers of America (2002). Principles on conduct of clinical trials and communication of clinical trial results. Available at: http://www.phrma.org/ publications/policy/2002-06-24.430.pdf Accessed April 16, 2004.

Pharmaceutical Research and Manufacturers of America (2004). PhRMA code on interaction with healthcare professionals.
Available at: http://www.phrma.org/publications/policy/200401-19.391.pdf Accessed April 16, 2004.

Public Health Service, Department of Health and Human Services (1995). Objectivity in research. Fed Regist 60: 35809-35819.

Rai AK, Eisenberg RS (2003). Bayh-Dole reform and the progress of biomedicine. Am Scientist 91: 52-59.

Relman AS (2001). Separating continuing medical education from pharmaceutical marketing. JAMA 285: 2009-2012.

Relman AS (2003). Defending professional independence: ACCME's proposed new guidelines for commercial support of CME. JAMA 289: 2418-2420.

Steinbrook R (2002a). Protecting research subjects - the crisis at Johns Hopkins. N Engl J Med 346: 716-720.

Steinbrook R (2002b). Improving protection for research subjects. $N$ Engl J Med 346: 1425-1430.

Steinbrook R (2004). Financial conflicts of interest and the NIH. $N$ Engl J Med 350: 327-330.

Warner TD, Gluck JP (2003). What do we really know about conflicts of interest in biomedical research? Psychopharmacology 171: $36-46$

Yarborough M, Sharp RR (2002). Restoring and preserving trust in biomedical research. Acad Med 77: 8-14. 